\title{
Decisive situations influencing continuous positive airway pressure initiation in patients with obstructive sleep apnea syndrome - A critical incident technique analysis from the personnel's perspective
}

\author{
Susanne Karlsson*1,2, Maria Elfström ${ }^{1,2}$, Ola Sunnergren ${ }^{1,3}$, Bengt Fridlund ${ }^{2}$, Anders Broström², 4 \\ ${ }^{1}$ Ear Nose and Throat Clinic, Ryhov County Hospital, Jönköping, Sweden \\ ${ }^{2}$ Department of Nursing Science, School of Health Sciences, Jönköping University, Jönköping, Sweden \\ ${ }^{3}$ Department of Clinical and Experimental Medicine, Division of Clinical Neurophysiology, Faculty of Health Sciences \\ Linköping University, Linköping, Sweden \\ ${ }^{4}$ Department of Clinical Neurophysiology, Linköping University Hospital, Linköping, Sweden
}

Received: June 13, 2014

DOI: $10.5430 /$ jha.v4n1p16
Accepted: October 26, 2014 Online Published: December 4, 2014

URL: http://dx.doi.org/10.5430/jha.v4n1p16

\begin{abstract}
Background: Continuous positive airway pressure is an effective treatment of obstructive sleep apnea syndrome, but adherence to treatment is low. Interventions such as encouragement, education and cognitive behavioural therapy have affected adherence to continuous positive airway pressure treatment positively. Currently there are no studies regarding the situation for personnel during the initiation process of treatment.

Purpose: The purpose was to describe situations influencing the initiation of continuous positive airway pressure in patients with obstructive sleep apnea syndrome from a personnel perspective.

Materials and methods: A qualitative approach using critical incident technique was used. Data were collected through semistructured interviews. Thirty one informants were strategically selected from sixteen centres in Sweden.

Results: Motivation, a prepared patient, communicational aspects and participation of family were described as pedagogical circumstances. External conditions, practical experience, the patient's state of health and adaption to the mask were described as practical circumstances. The personnel handled the situations in a theoretical, practical and/or an emotional way.

Conclusions: A better understanding of situations creating barriers or being facilitators, as well as ways to handle these situations, can be used to develop the role of personnel during the initiation process in order to increase continuous positive airway pressure adherence.
\end{abstract}

Key Words: Obstructive sleep apnea syndrome, Continuous positive airway pressure, Patient education, Healthcare personnel, Qualitative research

\section{Introduction}

The treatment of choice for obstructive sleep apnoea syndrome (OSAS) is Continuous positive airway pressure
(CPAP) which often is a life-long treatment. ${ }^{[1]}$ Sufficient pressure levels of CPAP prevent collapse of the upper airway which can eliminate apneas and hypopnoeas entirely,

*Correspondence: Susanne Karlsson; Email: susanne.036.140097@telia.com; Address: Ear Nose and Throat Clinic, Ryhov County Hospital, SE 55185 Jönköping, Sweden. 
improve sleep ${ }^{[2]}$ and cognitive function. ${ }^{[3]}$ Milleron et al. ${ }^{[4]}$ also showed that coronary heart disease was reduced over time with CPAP treatment. However, despite the positive effects of CPAP treatment and a reduction of symptoms as well as morbidity and mortality ${ }^{[5]}$ adherence tends to be poor. ${ }^{[6]}$ Haniffa et al. ${ }^{[7]}$ reported an adherent usage (i.e., $>4$ hours/night) ranging from $65 \%$ to $80 \%$ and an initial refusal to engage in treatment of $8 \%$ to $15 \%$. Early side-effects related to CPAP such as increased number of awakenings and dry mouth after 1-2 weeks are significantly associated to treatment dropout during the first year and machine usage time after six months. ${ }^{[8]}$ Other side-effects, such as blocked nose, skin irritations, mask leaks, ${ }^{[9]}$ and claustrophobia ${ }^{[10]}$ have also been shown to lower adherence. ${ }^{[11]}$

CPAP-treated patients perceive that information about OSAS (e.g., about apneas and sequelae) and CPAP (e.g., side effects) affect adherence to treatment positively, while a lack of support from personnel at the CPAP initiation makes it more difficult for the patient to use CPAP. ${ }^{[12]}$ Broström et al. ${ }^{[13]}$ found that there is a need for patient education about OSAS, its consequences and possible self-care before, as well as after, initiation of CPAP. Interventions from personnel, such as encouragement, education and cognitive behavioural therapy have been shown to affect adherence to CPAP positively. ${ }^{[14]}$

The guidelines of the American Academy of Sleep Medicine recommend that the initiation process of CPAP should include both oral and written information. ${ }^{[1]}$ The initial information should be delivered by a multidisciplinary management team including the referring physician, a sleep specialist, as well as other types of personnel. The function, care, and maintenance of the CPAP, as well as benefits and potential problems with the treatment, should also be covered at the first visit. Furthermore, patients should receive both close and long-term follow-up including education, help with practical difficulties and an evaluation of treatment adherence. ${ }^{[1]}$ Patient education is, from a general perspective described as the process of improving knowledge and skills in order to influence the attitudes and behaviour required to maintain and improve health. ${ }^{[15]} \mathrm{Pa}-$ tients who have an accurate understanding of their disease and CPAP adhere more to treatment. ${ }^{[16]}$ However, Tyrrel et $a l .{ }^{[17]}$ found that patients who had stopped CPAP during the first six months had a varying understanding of their disease and treatment despite receiving education. This might be related to various barriers for learning ${ }^{[12]}$ e.g., impairment of cognitive functions, ${ }^{[2]}$ depression ${ }^{[18]}$ and type $\mathrm{D}$ personality. ${ }^{[19]}$ Assessing psychological well-being and subjective health before initiating CPAP enables identification of patients who are non-adherent after one month. ${ }^{[16]}$

Previous interventions have been in line with the recommendations of the American Academy of Sleep Medicine and mainly focused on technical aspects related to the CPAP, education about OSAS and CPAP, support, or a combina-

Published by Sciedu Press tion of support and education. ${ }^{[6]}$ Despite the fact that all these types of interventions depend on the interaction between personnel and patients there are, to our knowledge, no studies focusing on situations during the initial initiation affecting the educational situation from the personnel perspective. Knowledge like this is of great interest for developing the role of personnel during the initiation process in order to increase patient adherence. The aim was to describe decisive situations influencing the initiation of CPAP to patients with OSAS from a personnel's perspective.

\section{Materials and methods}

\subsection{Design, setting and participants}

This study used a descriptive design, with the critical incident technique. ${ }^{[20]}$ The Critical incident technique is a systematic, inductive method used to collect descriptions of human behaviour in predefined situations, ${ }^{[21]}$ mainly through interviews. ${ }^{[22]} \mathrm{A}$ critical incident is the core concept and represents a decisive situation of great importance to the behaviour. Participants are asked to provide descriptions of specific incidents, experienced as either positive or negative, which they distinguish as significant for the aim of the study. ${ }^{[20]}$ The number of incidents required is dependent on the complexity of the study, although 100 incidents are usually sufficient for a qualitative analysis with a well-defined purpose. ${ }^{[23]}$ Thirty one participants were strategically selected from sixteen different centres in Sweden (covering $65 \%$ of all Swedish initiation centres) to ensure a maximal variation of descriptions. ${ }^{[24]}$ Study inclusion criteria were that the participants should have been clinically active concerning the initiation of CPAP with at least two months' experience. Demographic characteristics of the centres and personnel are shown in Tables 1 and 2.

\subsection{Data collection}

The study was examined and approved by the Ethical Review Board in Linköping, Sweden (Dnr: 2012/151-31) and was conducted in line with the declaration of Helsinki. Thirty nine staff members were contacted by letter after written consent was given by their managers. These staff members received information about the aim of the study, that their participation was voluntary, and that they could withdraw at any time without having to give a reason. They were also informed that the information they provided would be treated confidentially. A week after they received the letter, they were contacted by telephone and asked about participation in the study. Eight persons declined to participate because of logistical problems. After receiving informed written consent from the informants, semi-structured interviews were used to collect data. An interview guide consisting of three open main questions was constructed by three clinically active nurse researchers (SK, ME, AB) all with good experience of OSAS and good 
knowledge of the critical incident technique. The first two questions concerned situations that worsened or facilitated the initiation process and the third question focused on how these situations were managed by the personnel (see Table 3). Two pilot interviews were performed to validate the interview guide. The interview questions and procedure worked well and the interviews were therefore included in the analysis. The interviews were conducted between April 2011 to March 2012 jointly by two researchers (SK, ME) and were recorded with a digital voice recorder. The interviews lasted up to 50 minutes with an average length of 25 minutes. The interviews were transcribed word for word resulting in 216.5 pages of text (1.5 line spacing, font 12).

Table 1: Clinical data of the CPAP centres

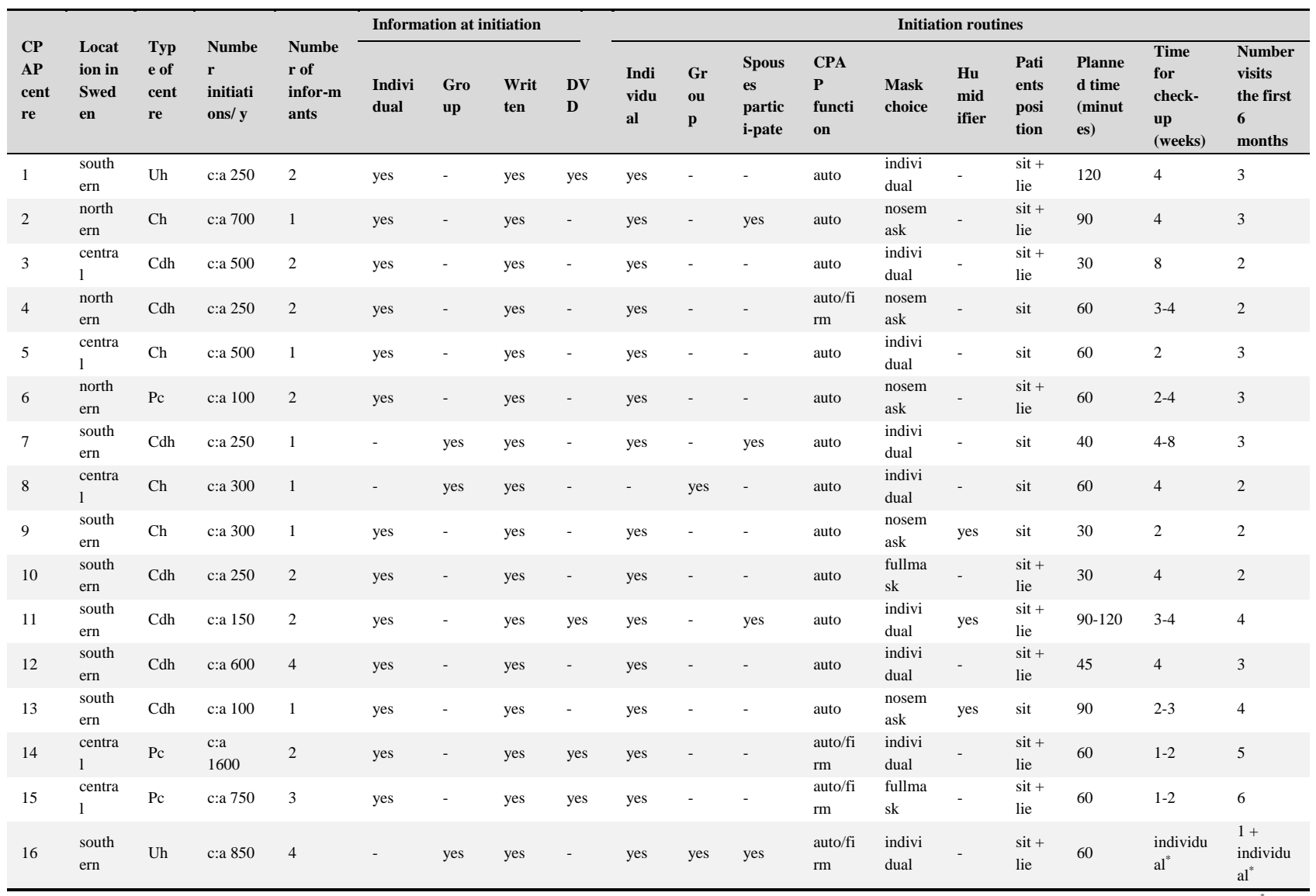

Note. Uh = University hospital; $\mathrm{Ch}=$ County hospital; $\mathrm{Cdh}=$ County district hospital; $\mathrm{Pc}=$ Private clinic; auto = auto CPAP; firm = firm pressure CPAP; sit = sitting initiation; sit + lie = sitting and lying initiation; ${ }^{*}$ drop in when necessary and planned follow-up after 1 year.

\subsection{Data analysis}

The transcribed interviews were first read several times individually by two of the researchers (SK, ME) to obtain a sense of the whole. In the data reduction, two researchers (SK, ME) first individually marked and then together discussed situations identified as decisive, in order to reach a consensus. A situation, either positive or negative, was considered as decisive if it was related to the aim of the study. A total of 467 decisive situations and 492 situations describing how situations were managed were identified. Saturation was reached after around 28 interviews. At the beginning of the categorization, the situations were extracted from the text individually by the researchers (SK, $\mathrm{ME}$ ) and placed into groups. The final categorization concerning situations that affected the CPAP initiation resulted in 34 subcategories allocated to eight categories and two main areas. The final categorization for the management of the situations resulted in 31 subcategories allocated to nine categories and three main areas. The categories described the general structure of the subcategories, while the main areas described the overall structure of the material. ${ }^{[25]}$ To increase credibility, researcher triangulation was used when the situations were identified and categorized. The nurse researchers (SK, ME) together with the supervisor (AB), who has good methodological knowledge, independently classified the subcategories, categories and main areas by means of an inductive process. Through a dialogue and interaction concerning the whole and the integrated parts, the categories were then compared and revised until a consensus regarding the classification was reached. 
Table 2: Demographic data of the informants

\begin{tabular}{|c|c|c|c|c|c|}
\hline Personnel & Sex & Age (year) & Education & CPAP experience (year) & Centre/location in Sweden \\
\hline 1 & $\operatorname{man}$ & $41-50$ & $\mathrm{~N}$ & 6 & Uh/southern \\
\hline 2 & woman & $51-60$ & $\mathrm{~N}$ & 6 & Uh/southern \\
\hline 3 & Woman & $>60$ & BMA & 6 & $\mathrm{Ch} /$ northern \\
\hline 4 & man & $<40$ & $\mathrm{~N}$ & 2 month & Cdh/central \\
\hline 5 & woman & $41-50$ & NA & 4 & Cdh/central \\
\hline 6 & woman & $51-60$ & BMA & 13 & Cdh/northern \\
\hline 7 & woman & $51-60$ & BMA & 3 & Cdh/northern \\
\hline 8 & woman & $51-60$ & $\mathrm{~N}$ & 20 & $\mathrm{Cd} /$ central \\
\hline 9 & woman & $41-5$ & NA & 3 & Pc/northern \\
\hline 10 & man & $51-60$ & NA & 20 & Pc/northern \\
\hline 11 & woman & $<40$ & $\mathrm{~N}$ & 4 & Cdh/southern \\
\hline 12 & woman & $41-50$ & $\mathrm{~N}$ & 3 & $\mathrm{Cd} /$ central \\
\hline 13 & man & $41-50$ & $\mathrm{~N}$ & 10 & Cd/southern \\
\hline 14 & woman & $41-50$ & $\mathrm{~N}$ & 10 & Cdh/southern \\
\hline 15 & woman & $41-50$ & $\mathrm{~N}$ & 11 & Cdh/southern \\
\hline 16 & woman & $51-60$ & $\mathrm{~N}$ & 19 & Cdh/southern \\
\hline 17 & man & $51-60$ & $\mathrm{~N}$ & 4 & Cdh/southern \\
\hline 18 & woman & $41-50$ & BMA & 4 & Cdh/southern \\
\hline 19 & woman & $<40$ & $\mathrm{~N}$ & 8 month & Cdh/southern \\
\hline 20 & woman & $<40$ & $\mathrm{~N}$ & 11 & Cdh/southern \\
\hline 21 & woman & $41-50$ & $\mathrm{~N}$ & 7 & Cdh/southern \\
\hline 22 & woman & $51-60$ & $\mathrm{~N}$ & 5 & Pc/central \\
\hline 23 & woman & $51-60$ & BMA & 16 & Pc/central \\
\hline 24 & woman & $41-50$ & BMA & 12 & Pc/central \\
\hline 25 & woman & $>60$ & $\mathrm{~N}$ & 6 & Pc/central \\
\hline 26 & woman & $51-60$ & $\mathrm{~N}$ & 13 & Pc/central \\
\hline 27 & Woman & $>60$ & BMA & 5 & Uh/southern \\
\hline 28 & woman & $51-60$ & BMA & 22 & Uh/southern \\
\hline 29 & woman & $<40$ & $\mathrm{~N}$ & 8 & Uh/southern \\
\hline 30 & woman & $51-60$ & NA & 9 & Uh/southern \\
\hline 31 & woman & $41-50$ & $\mathrm{~N}$ & 5 & Cdh/southern \\
\hline
\end{tabular}

Note. $\mathrm{N}=$ nurse; $\mathrm{BMA}=$ biomedical analyst; $\mathrm{NA}=$ nursing assistant; $\mathrm{Uh}=$ university hospital; $\mathrm{Ch}=$ County hospital; Cdh = County district hospital; Pc = private clinic

\section{Results}

\subsection{Decisive situations}

\subsubsection{Pedagogical circumstances}

Motivation, a prepared patient, communicational aspects and a participation of family/friends influenced the pedagogical process (see Figure 1). Categories, subcategories and quotations are presented in Table 4.

A negative attitude affected the patient's motivation negatively and as a consequence the pedagogical process. Patients who had received information from other personnel before the initiation, had received positive information about CPAP from a friend and/or family, or if they had searched for information by themselves were more motivated. A patient who had time to reflect had an increased understanding of the treatment and also the educational procedure evolved into a different situation with more relevant questions asked by the patient. Motivation was associated with the presence of OSAS symptoms. Patients who wanted CPAP facilitated for the personnel by having a high motivation to get a well-functioning treatment. It was described as difficult to motivate patients with few symptoms because they did not feel the relief of symptoms, had difficulties to accept the treatment, and/or did not realize the long-term consequences of not using CPAP. Personnel described it as 
"being under pressure" because they thought they had only one chance to change the patients' attitude. It was more time-consuming when they repeatedly had to explain the pathophysiology of OSAS, nor could they use the symptoms as pedagogical tools to increase motivation.

Table 3: The interview guide used during the interviews with the personnel

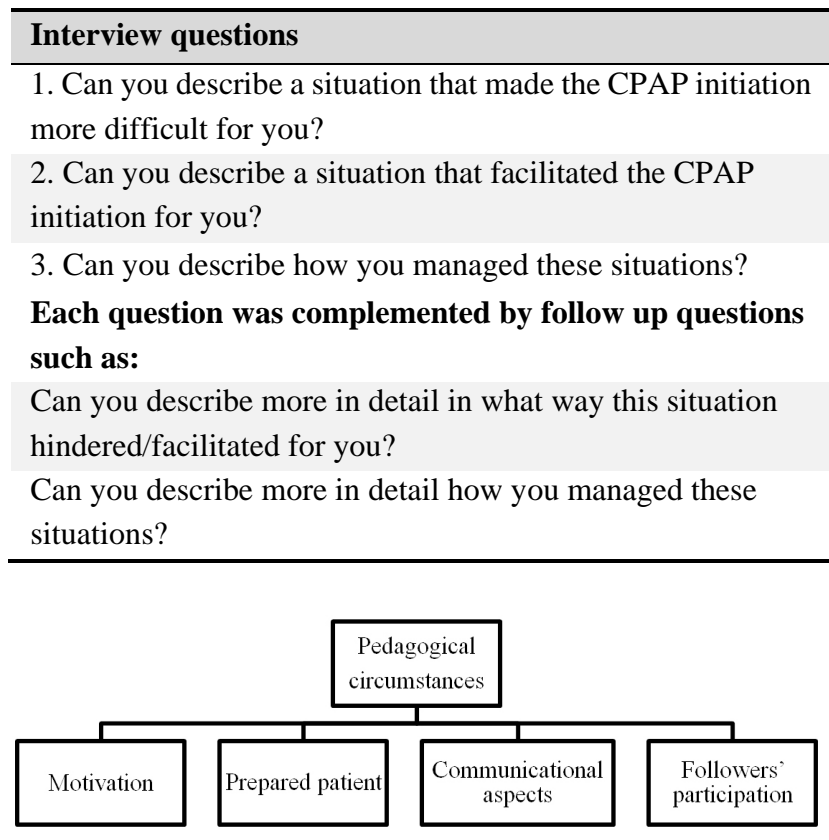

Figure 1: A description of decisive situations influencing pedagogical circumstances during the initiation of CPAP for patients with OSAS

Communication was described either as a barrier or a facilitator. A positive interaction was described as important to ensure good communication, trust and collaboration with patients. The communication could be a problem if the patient had a cognitive dysfunction. Too much information was complicating communication and the patients could have difficulties to remember. Patients who caused a distraction during the outline of the information affected the communication negatively. Cultural and linguistic barriers were described as making the communication more problematic. They also described the difficulty of communicating with a third part. The partners who had accompanied the patients were described as impeding the pedagogical process when they took over the conversation and spoke on their partners' behalf. Personnel also described how support from a partner could facilitate the pedagogical process since there were two people who had heard the information.

\subsubsection{Practical circumstances}

External conditions, practical experience, the patient's state of health and adaption to the mask influenced practical circumstances during the initiation process (see Figure 2). Cat- egories, subcategories, and quotations are presented in Table 4.

Personnel described that external conditions such as being available for the patients on the phone and through frequent follow-up visits facilitated the possibility to manage problems. It was also important to have the right tools and equipment since it made it easier to try out the mask and machine. On the other hand, lack of material and premises affected the initiation negatively. Personnel also expressed that it was important to have sufficient time to avoid stress. Patients with previous technical experience facilitated the initiation.

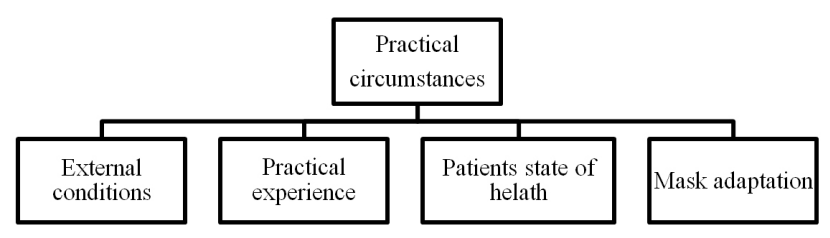

Figure 2: A description of decisive situations influencing practical circumstances during the initiation of CPAP for patients with OSAS

Longer clinical experience increased the ability to find a suitable mask. Patients or personal care assistants with a poor technical knowledge made the initiation difficult since their problems created resentment. Patients with previous mask experience accepted the treatment more easily. The patients' state of health made it difficult to optimize the treatment since they did not know how high CPAP pressure the staff members dared to use on a patient with comorbidities. It was also difficult to initiate the CPAP on a patient with insomnia or a cold. Patients with functional impairments were also described as affecting the initiation negatively. Having an unusual face, or a beard, an allergy or a panic for the mask were other negative elements.

\subsection{Managing of decisive situations}

Three different types of behavior for managing situations were identified: theoretical handling (see Figure 3), practical handling (see Figure 4) and emotional handling (see Figure 5). Categories, subcategories and quotations are presented in Table 5.

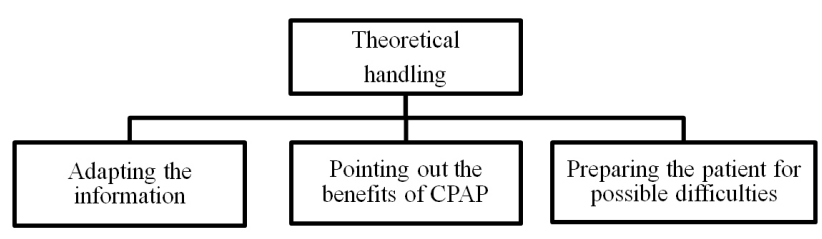

Figure 3: A description of theoretical handling of situations during the initiation of CPAP for patients with OSAS 
Table 4: Categorization of decisive situations negatively or positively affecting the initiation of CPAP for patients with OSAS

\begin{abstract}
Meaning Units
"The more tired the patients are, or if they have a headache the easier it is to motivate them, because it only takes one or two nights until they get rid of their headaches. It is easy to motivate them by telling them this." (I:21)

"Something that facilitates a lot is that if the patient himself has sought help and really wants to be helped. These patients are incredibly motivated." (I:29)

"Those patients who have a high AHI, but no symptoms, for example no daytime sleepiness, they are very

difficult to motivate." (I:20)

"They can be negative, it makes it harder. It's like you right from the start struggle in an uphill battle." (I:11)

"They got a brochure with information to take home to read. This greatly facilitates for us when they come back to us for a CPAP initiation, because they have relevant questions about things they are wondering about. They are prepared when they come to us and that's very good." (I:31)

"Most people are well informed and they know what kind of device or mask they would like to have when they get here. In this way, you don't need to provide the same information about details as you have to do when you have a patient who doesn't know anything." (I:16)

"If they have a family member with CPAP treatment, such as the wife. Then, they have already seen the device physically, how it looks and how it works. They also know that it effectively eliminates apneas, yes they know it works." (I:4)

"I see quite a big difference in cases when the patient goes home after the visit to the physician and comes back for CPAP initiation at a later date. The patient has had time to reflect and is more receptive." (I:19)

"I think it's incredibly important to have a good first impression, a positive attitude after the first visit. It sets the starting point for us to have a good relationship, communication and collaboration." (I:12)

"At this stage, they are often cognitively impaired and slow in their thinking, cannot focus. You can see that it takes time for them to respond. I can often hear a lag in the response." (I:1)

"Sometimes it's too much information and they often say when they come back for the follow-up visit, 'I've never heard of this before', and you know that it's not possible because it's something that we always provide information about. But they are so overcrowded with information that they find it difficult to remember." (I:5) "It's more difficult if they have a lot of questions, because you can lose your "thread" when you're trying to answer. You easily forget what you have said and where you were in the information process." (I:18)

"If they have problems with the language, if they don't understand Swedish, you sometimes wonder if they really understood correctly." (I:18)

"Patients with several personal care assistants, there you see a problem. There is no problem to provide information to one person, but it is meant to be passed on, and as soon as the information is forwarded to a third party is not the same as it was in the beginning." (I:13)
\end{abstract}

"If they have family members who wants to take over the situation and not let the patient speak. Such things can make it more difficult, when the family decides." (I:30)

"I think it's great if they have a family member with them, because it facilitates. They are two people who have heard the information and can remember how it should be and how to fit the mask." (I:22)

"It makes it easier for us in our work, that we are available for the patients. They have the opportunity to call every day since we have telephone time every day and an ability to offer support." (I:15)

"With the newest machines, it's easier. Then you know what pressure to start with, the machine takes care of that itself." (I:28)

"There are patients who need to just pull the mask over their head, but the straps tend to be harder and shorter. Some patients get "disqualified" with these new masks, they can't get them on." (I:10)

"Timewise it is good, I think that makes it work. I don't need to feel any stress to be able to get ready for the next (patient), you feel that you can sit and feel relaxed." (I:20)

"Lack of time can make it more difficult, if I have a lack of time or if the patient has a lack of time. Then you get stressed and cannot say what you need to say." (I:30)

"If they easily understand technical equipment, it facilitates." (I:13)

"Then they say, "O my goodness! I have no knowledge about technology”, they have decided that beforehand." (I:27)

"When you have patients that work with occupations where they wear masks, firefighters that have worked with gas masks. It is very easy.” (I:2)

"The more you have worked with CPAP initiation, the more you get a certain feeling for it, which mask to use. You see it almost at once." (I:25)

"I, who have not worked that long know which (masks) we have, but don't know about the different fabrics that we also can try." (I:19)

"Many of them have multiple diseases like severe obesity, they might have different heart conditions too, plus

they have this sleep apnea. Then there are more medical aspects involved, you have to think about what pressure you can use, how high you dare to go." (I:22)

"Something that bothers a lot is those who have both sleep apnea and insomnia. It's not unusual at all. It's almost impossible to get the treatment to work on them. They cannot fall asleep." (I:2)

"Sometimes for example they have a bad cold when they get here and then you can't try out the CPAP." (I:22)

"A patient with clumsy fingers, elderly immobile patients or those who have had a stroke and can use only one hand and patients in wheelchairs, then you have to make special arrangements." (I:10)

"All people have different face shapes and it's up to you to try out a mask that fits this particular shape.

Sometimes it can be really difficult, there are those who have very narrow faces, perhaps a large hooked nose and then there are the ones that have an almost round faces." (I:25)

"It is difficult if they have a beard. Those who are not willing to shave it off, if it doesn't work with the mask adaption, because it's often too much leakage." (I:11)

"Some of them are allergic to most masks because they get a rash. Then it can get very problematic to get a proper mask for the patient." (I:6)

"If they feel panic just by putting the mask on, then it's difficult to continue the tryout." (I:20)

\begin{tabular}{lll} 
Subcategories & Categories & Main Areas \\
\hline $\begin{array}{l}\text { Patients with symptoms of OSAS are } \\
\text { easy to motivate (26) }\end{array}$ & Motivation & $\begin{array}{l}\text { Pedagogical } \\
\text { circumstances }\end{array}$ \\
$\begin{array}{l}\text { Patients who want CPAP treatment } \\
\text { (16) }\end{array}$ & \\
Patients with few symptoms of & & \\
OSAS are difficult to motivate (13) & & \\
Negative attitude (70) & &
\end{tabular}

Received information from other personnel (14)

Prepared patient

Patients who have searched for

information (19)

Received positive information about

CPAP from a friend/family (17)

Patients who had time to reflect (2)

Positive interaction (14)

Communicational

aspects

Cognitive dysfunction (24)

Too much information (9)

Patients who distracts during the outline of the information (10)

Cultural and linguistic barriers (30)

Difficulties to communicate with a third part (5)

\section{Spouses decides (7)}

Followers' support in the pedagogical process (25)

To be available for the patient (6)

To have the right tools and equipment (17)

Lack of material and premises (10)

To have sufficient time (5)

Lack of time (16)

Patients with technical experience (7)

Low level of technical knowledge

(14)

Patients with experience of mask use (4)

Long clinical experience (13)

Short clinical experience (2)

Co-morbidity (4)

Patients state of

health

Insomnia (3)

Patients with a cold during the

initiation (2)

Patients with functional impairments

(19)

Different shape of the patients' faces (12)

Followers'

participation in the

pedagogical process

Practical

circumstances

Published by Sciedu Press

Patients with a beard (4)

Patients allergic to the mask (1)

Patients with panic for the mask (27) 


\subsubsection{Theoretical handling}

The personnel adapted the information, pointed out the benefits of CPAP and prepared the patient for possible difficulties. They simplified the information when they thought that the patient could not embrace all the information. The information was also divided to before and after the mask adjustment. They used body language and wore a mask themselves to show how it would look. The personnel also repeated and extended the time to provide information and clarified the physicians' information and provided written educational material.

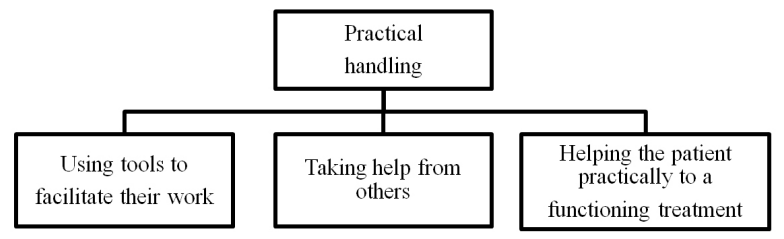

Figure 4: A description of practical handling of situations during the initiation of CPAP for patients with OSAS

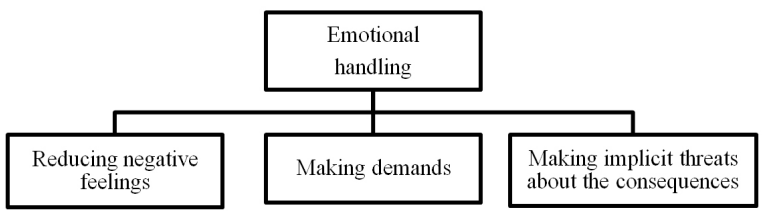

Figure 5: A description of emotional handling of situations during the initiation of CPAP for patients with OSAS

The personnel pointed out the benefits of CPAP by giving information about the positive effects. They highlighted treatment improvements and that it prevented other diseases. They used other patients' positive experiences to motivate. They also talked about the positive effects with partners and personal care assistants to motivate them to help. They prepared the patients for possible difficulties and gave information about how the treatment might feel. They used exaggerations, e.g., that the treatment could be uncomfortable, so the patients would be positively surprised. They also clarified that everyone does not feel a quick improvement and that it was important to struggle on. Furthermore, they gave advice about how the patients could get used to the treatment. Patients who thought it was too difficult to sleep with the mask on were advised to take the mask of so that they could use it more hours the next night.

\subsubsection{Practical handling}

Practical handling was described as using tools to facilitate the work, taking help from others and helping the patient practically towards having a functioning treatment (see Figure 4). The personnel described that they used a checklist to ensure that they would not miss anything. When the patients came back for a checkup they used a questionnaire describing symptoms so they could point out improvements. An- other tool was to use data from the device to show positive treatment effects when the patients did not experience improvements. They also used their own practical experiences to make it easier to show the patients.

The personnel described that they took help from partners in order to motivate and support the patients. They used colleagues to look at downloaded data and they contacted physicians to discuss treatment options, as well as having contacted the ward so the patient could try out the CPAP at the hospital. The personnel also contacted personal care assistants to help patients who had problems handling the CPAP at home.

The personnel described that they let the patients try different kinds of masks, test different soft parts or head bands. They offered the patient to lie down in a bed when trying the mask on, in order to enhance comfort. The patients were also offered to take different masks home. If the patients suffered from side-effects they got help with different adjustments. They could also switch to a different device. The personnel described that they initially chose a simple device. They also locked features of the device to reduce possibilities to access various functions by mistake. Professional drivers could get two masks, one to have in their vehicle and one to have at home.

They trained practical moments gradually. If the patients felt fear or panic the first step was to only talk about the treatment and then start training gradually. Breathing exercises were performed with the patients to facilitate breathing in the mask. The patient also got to practice in front of a mirror to identify the difference between a good or bad mask fit. They also allowed the patients to press the buttons and start the device themselves so that they would dare to handle it at home. The personnel took more time for practical moments. The patients were allowed to fall asleep with the mask on so they would get the chance to twist and turn with it while lying down. They also gave increased telephone or mail access, and gave more frequent follow-up visits to prevent difficulties.

\subsubsection{Emotional handling}

Emotional handling was described as reducing negative feelings, making demands and making implicit threats about the consequences of OSAS and non-adherence (see Figure 5). The personnel reduced the patients' negative feelings by talking about the CPAP being nothing to be ashamed of. They encouraged laughter to make the patients more relaxed. They helped the patients to perceive the treatment less dramatic by speaking in metaphors (e.g., CPAP is like a crutch for breathing). They tried to create trust by avoiding leaving the patients alone during the initiation. They wanted the first meeting to be positive to create a good relationship. They were completely focused on how the patients expressed their feelings and showed interest in their questions and experiences. 
Table 5: Categorization of how personnel handled decisive situations at the CPAP initiation

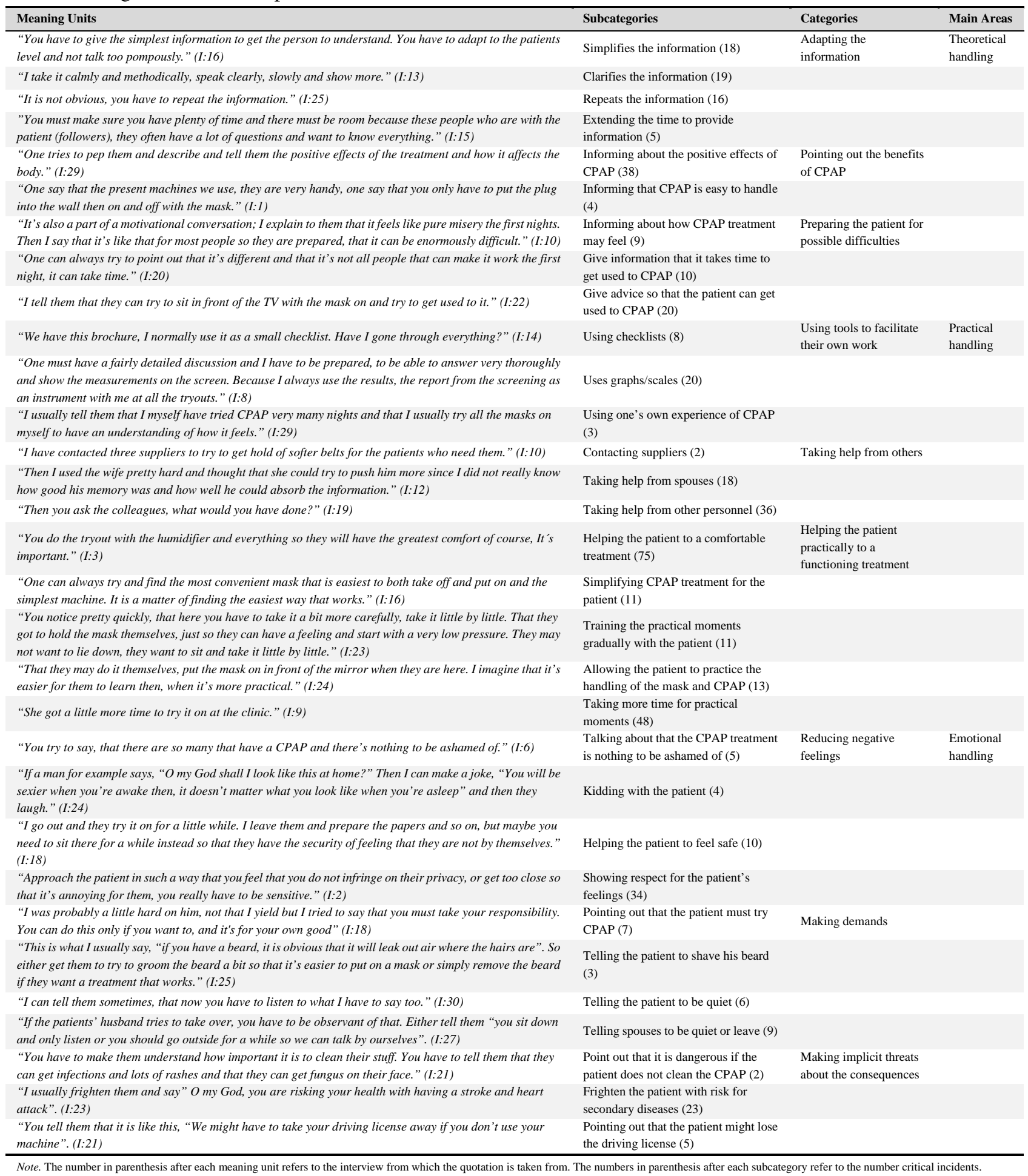

Note. The number in parenthesis after each meaning unit refers to the interview from which the quotation is taken from. The numbers in parenthesis after each subcategory refer to the number critical incidents.

The personnel sometimes had to make demands that the patients should take responsibility for their treatment since the tryout time was limited. Sometimes they had to tell a patient to shave off his beard, otherwise he had to accept a leakage. The personnel described that they had made implicit threats about the risks of suffering some serious consequences from infections and rashes if not cleaning the mask.
They sometimes had to frighten the patients with the risk for co-morbidities. They described the pathophysiology related to apneas and that it would lead to serious consequences if they did not use the CPAP. They also pointed out the risk that the patients might lose their driving license if not using the CPAP. 


\section{Discussion}

This study set out to describe decisive situations influencing initiation of CPAP to patients with OSAS from a personnel perspective. We identified a great variety of decisive situations negatively or positively affecting the initiation of CPAP to patients with OSAS (see Table 4), as well as different ways of handling these situations (see Table 5). To the best of our knowledge, no other study has described the in-depth perspective of situations affecting personnel during the initiation of CPAP.

That patients and spouses with a negative attitude were more difficult to motivate was reported by the personnel. This can be explained by the fact that these patients did not experience any suffering from their disease. Patients who had symptoms were, on the other hand, described as easier to motivate since they had suffered from something that they wanted to get rid of. Drieschner et al. ${ }^{[26]}$ have suggested that motivation to engage in treatment is dependent on six cognitive and emotional internal determinants: problem recognition, level of suffering, external pressure, perceived cost of treatment, perceived suitability of treatment, and outcome expectancy. External factors such as treatment, circumstances, situations, demographic factors, and type of problems have an effect on the internal determinants. ${ }^{[26]}$ The self-determination theory implies that motivation is dependent on human autonomy which can be seen on a continuum. At one end of this continuum is a behaviour that is motivated by external regulation, which means that the individual performs a task because he/she has been told to do so. At the other end are behaviours that are intrinsically motivated and performed for their own sake. Our findings revealed that the personnel met patients who expressed negative attitudes and did not want treatment, which can be seen as a lack of intrinsic motivation. Self-determination is dependent on competence, independence and a sense of belonging. ${ }^{[27]}$ Education related to the handling of the CPAP is of great importance during the initiation, but personnel should avoid focusing only on practical aspects. It may therefore, from a behavioural perspective, be of importance that the initiation is adapted to the specific situation and include suitable interventions to increase the intrinsic motivation to use CPAP. Cognitive behavioural therapy has been used with positive effects on adherence, ${ }^{[6]}$ but more studies should be conducted combining theoretical and practical aspects with behavioural interventions in order to increase motivation.

We found that prepared patients facilitated the pedagogical process because they already had knowledge and an understanding of their situation. Patients with an accurate perception of their illness and treatment have in previous studies been shown to be more adherent to CPAP. ${ }^{[16]}$ However, Tyrrel et al. ${ }^{[17]}$ found that patients despite patient education had a varying understanding about OSAS, its symptoms, risks and CPAP treatment. Poulet et al. ${ }^{[16]}$ mean that the result is dependent on how the patients perceive their health, their disease and the risks involved with it. Previous research has also shown that the patients' trust in personnel also has importance for adherence. ${ }^{[16]}$ Furthermore, cognitive impairment may be a barrier for the pedagogical process in patients with OSAS. ${ }^{[2]}$ We identified several situations related to cognitive impairment that influenced the pedagogical process negatively. Patients who were cognitively impaired caused problems since they could not absorb all the information. The personnel therefore had to adapt the conversation, give shorter, simplified and repeated information so the patients would understand. An interactive communication process was also important. Rather controversially the personnel in the present study described that followers participation may impede the initiation. Spouses life situation are strongly affected both before ${ }^{[28]}$ and after initiation of CPAP. Elfström et al. ${ }^{[29]}$ found that spouses supported the patient a great deal and that it facilitated their support when they had been involved during the initiation, and thus received the same information as the patient. One might therefore conclude it is of great importance for personnel to have spouses/partners present during the initiation.

Habits have been described as learned sequences of actions carried out without conscious thinking or reflection, and often without any sense of awareness. The actions have become an automatic response to contextual cues (e.g., a specific time or place). ${ }^{[30,31]}$ A habit can be formed by means of implementation intentions: plans for when, where and how the behaviour is performed. ${ }^{[32]}$ In the present study, this can be applied to the personnel's handling when for instance they gave advice about how the patient could get used to the CPAP. The CHI-5, a tool to identify if and when habits are formed has recently been developed for CPAP-treated patients. ${ }^{[33]}$ It can be used during the initiation in tailored interventions of practical, theoretical and/or emotional type. A kind of motivational interviewing (i.e., a collaborative and person-centred form of guidance) can be used by personnel during the communication with the patient and/or partner with the aim to enhance intrinsic motivation and strengthen the patient's own arguments and reasons. ${ }^{[34]}$ Future studies should focus on how communication between personnel and patients and partners can affect motivation, habit formation and adherence.

The personnel in the present study described that external conditions, practical experience, and patients' state of health, as well as problems with mask adaptation affected them during the initiation. It is common that patients experience side-effects related to the mask ${ }^{[35]}$ and that these sideeffects causes low adherence. ${ }^{[11]}$ The American Academy of Sleep Medicine's guidelines recommend that patients should be informed about the handling, benefits and possible problems with the treatment. ${ }^{[1]}$ The personnel in the present study therefore prepared the patient concerning that the treatment could be difficult in order to lower expecta- 
tions and perceived costs of the treatment. On the other hand, personnel also described the importance of informing the patient about positive effects of the CPAP and how it may feel. Broström et al. ${ }^{[36]}$ found that group education could mean practical and emotional support from other patients. Patients were able to identify themselves with, and talk to other group members who had the same problems. In the present study personnel used emotional handling during the communication to reduce negative feelings. It was important to show respect for the patients' feelings and autonomy and to work as a team with them to reach a form of shared decision-making. A common description of shared decision-making is that it involves at least two people (e.g. a member of the staff and a CPAP patient) that share information, and that they together agree on the choice of action (e.g., a change of mask). This may also mean that they will agree on not doing anything. ${ }^{[37]}$ Shared decision-making can also be achieved when personnel explain the disease to the patient, present other treatment options (e.g., oral appliances), and discuss the benefits and risks. It can also mean to clarify the patient's values, discuss the opportunities, present what is known and make recommendations. It is important to check the patient's understanding, make joint decisions and arrange for the follow-up. ${ }^{[38]}$ Shared decisionmaking has not been studied in a CPAP context, but it might be effective in achieving increased adherence.

\section{Limitations}

This study has some limitations which must be recognized when interpreting the results. Rigour in a qualitative study can be judged against the concepts of applicability, concordance, security, and accuracy. ${ }^{[24]}$ The chosen method seemed appropriate since the aim of the study was to describe situations influencing the initiation of CPAP from a personnel's perspective. Thirty-one members of staff, well in line with methodological recommendations critical incident technique, ${ }^{[23]}$ were strategically chosen and gave a rich variation of demographic data, decisive situations and han- dling of the situations. The interviews created good opportunities to describe representative behaviours since the interviewer asked follow-up questions until sufficient information was obtained. This increases the applicability of the study.

It is clear that data can be categorized in more than one way when using critical incident technique, but it is always possible to refer back to the critical incidents. ${ }^{[19]}$ In this study, 467 decisive situations influencing the initiation and 492 situations describing management of situations were collected in the interviews. This must be considered adequate to carry out a meaningful and secure analysis. ${ }^{[23]}$ We also used researcher triangulation and repeated comparisons between raw data and the final findings to increase security and accuracy. Furthermore, accuracy was established by using statements connected to the categories. Saturation was reached after 27 interviews, which increased the applicability and concordance.

However, the use of an inductive qualitative method caused difficulties in obtaining a representative sample in a statistical sense, thus limiting the possibilities of generalizing the findings.

\section{Conclusions}

The findings showed that: external conditions, practical experience, the patient's state of health and adaption of the mask were practical circumstances that negatively or positively affected personnel during the initiation. Motivation, a prepared patient, communication and a partners' participation were pedagogical circumstances that negatively or positively affected personnel during the initiation. The personnel handled the situations in a theoretical, practical and/or emotional way. A better understanding of barriers and facilitators as well as different ways to handle these situations can be used to improve and develop the initiation of CPAP in order to increase adherence.

\section{References}

[1] Epstein LJ, Kristo D, Strollo, PJ. Clinical guideline for the evaluation, management and long-term care of obstructive sleep apnea in adults. Adult Obstructive Sleep Apnea Task Force of the American Academy of Sleep Medicine. J Clin Sleep Med. 2009; 5: 263-76. PMid: 19960649.

[2] Banno K, Kryger MH. Sleep apnea: clinical investigations in humans. Sleep Med. 2007; 8: 400-26. PMid: 17478121. http://dx .doi.org/10.1016/j.sleep.2007.03.003

[3] Ferini-Strambi L, Baietto C, Di Gioia MR, Castaldi P, Castronovo $\mathrm{C}$, Zucconi $\mathrm{M}$, et al. Cognitive dysfunction in patients with obstructive sleep apnea (OSA): partial reversibility after continuous positive airway pressure (CPAP). Brain Res Bull. 2003; 61: 87-92. http://dx.doi.org/10.1016/S0361-9230(03)00068-6
[4] Milleron O, Pillière R, Foucher A. Benefits of obstructive sleep apnoea treatment in coronary artery disease: a long-term followup study. E Heart J. 2004; 25: 728-34. PMid: 15120882. http: //dx.doi.org/10.1016/j.ehj.2004.02.008

[5] Marin JM, Carrizo SJ, Vicente E, Augusti AG. Long-term cardiovascular outcomes in men with obstructive sleep apnoea-hypopnoea with or without treatment with continuous positive airway pressure: an observational study. Lancet. 2005; 365: 1046-53. http: //dx.doi.org/10.1016/S0140-6736(05)71141-7

[6] Weaver TE, Sawyer AM. Adherence to continuous positive airway pressure treatment for obstructive sleep apnoea: implications for future interventions. Ind J Med Res. 2010; 131: 245-58. PMid: 20308750.

[7] Haniffa M, Lasserson TJ, Smith I. Interventions to improve compliance with continuous positive airway pressure for obstructive sleep apnoea. Cochrane Database of Systematic Reviews 4: 
CD003531. 2009. http://dx.doi.org/10.1002/14651858.CD 003531.pub2

[8] Ulander M, Johansson MS, Ewaldh AE, Svanborg E, Broström A. Side effects to continuous positive airway pressure treatment for obstructive sleep apnoea: changes over time and association to adherence. Sleep Breath. 2014 Feb 21. [Epub ahead of print] PMid: 24557772. http://dx.doi.org/10.1007/s11325-014 $-0945-5$

[9] Olsen S, Smith S, Oei TPS. Adherence to continuous positive airway pressure therapy in obstructive sleep apnoea sufferers; a theoretical approach to treatment adherence and intervention. Clin Psych Rev. 2008; 28: 1355-71. PMid: 18752879. http://dx.doi.org/10. $1016 / j . c p r .2008 .07 .004$

[10] Chasens E, Pack A, Maislin G, Dinges D, Weaver T. Claustrophobia and adherence to CPAP treatment. West J Nurs Res. 2005; 27 : 307-21. PMid: 15781905. http://dx.doi.org/10.1177/01939 45904273283

[11] Baltzan MA, Elkholi O, Wolkove N. Evidence of interrelated side effects with reduced compliance in patients treated with nasal continuous positive airway pressure. Sleep Med. 2009; 10: 198-205. PMid: 18314388. http://dx.doi.org/10.1016/j.sleep. 200 7.12 .005

[12] Broström A, Nilsen P, Johansson P, Ulander M, Strömberg A, Svanborg E, et al. Putative facilitators and barriers for adherence to CPAP treatment in patients with obstructive sleep apnea syndrome: A qualitative content analysis. Sleep Med. 2010; 11: 126-30. PMid: 20004615. http://dx.doi.org/10.1016/j.sleep. 200 9.04.010

[13] Broström A, Johansson P, Albers J, Wiberg J, Svanborg E, Fridlund B. 6-month CPAP-treatment in a young male patient with severe obstructive sleep apnoea syndrome-a case study from the couple's perspective. Eur J Card Nurs. 2008; 7: 103-12. PMid: 17291832. http://dx.doi.org/10.1016/j.ejcnurse.2006.11.004

[14] Smith I, Nadig V, Lasserson TJ. Educational, supportive and behavioural interventions to improve usage of continuous positive airway pressure machines for adults with obstructive sleep apnoea. Cochrane Database of Systematic Reviews 2: CD007736. 2009. http://dx.doi.org/10.1002/14651858.CD007736

[15] Rankin SH, Stallings KD. Patient education, principles and practice. Philadelphia, Lippincott Williams and Wilkins, (4Th edition). 2001.

[16] Poulet C, Veale D, Arnol N, Lévy P, Pepin JL, Tyrrell J. Psychological variables as predictors of adherence to treatment by continuous positive airway pressure. Sleep Med. 2009; 10: 993-99. PMid: 19332381. http://dx.doi.org/10.1016/j.sleep. 200 9.01.007

[17] Tyrrell J, Poulet C, Pépin J-L, Veale D. A preliminary study of psychological factors affecting patients' acceptance of CPAP therapy for sleep apnoea syndrome. Sleep Med. 2006; 7: 375-79. PMid: 16564221.http://dx.doi.org/10.1016/j.sleep. 200 5.10 .005

[18] Saunamäki T, Jehkonen M. Depression and anxiety in obstructive sleep apnea syndrome: a review. Acta Neur Scand. 2007; 116: 277 88. PMid: 17854419. http://dx.doi.org/10.1111/j.1600-0 404.2007.00901.x

[19] Broström A, Strömberg A, Mårtensson J, Ulander M, Harder L, Svanborg E. Association of type D personality to perceived side effects and adherence in CPAP-treated patients with OSAS. J Sleep Res. 2007; 16: 439-47. PMid: 18036091. http://dx.doi.org/1 $0.1111 / j .1365-2869.2007 .00620 . x$

[20] Flanagan JC. The critical incident technique. Psych Bull. 1954; 51: 327-358. http://dx.doi.org/10.1037/h0061470

[21] Keating D. Versatility and flexibility: attributes of the critical incident technique in nursing research. Nurs Health Sc. 2002; 4: 33-41. http://dx.doi.org/10.1046/j.1442-2018.2002.00099.x
[22] Schluter J, Seaton P, Chaboyer W. Critical incident technique: a user's guide for nurse researchers. J Adv Nurs. 2008; 61: 10714. PMid: 18173737. http://dx.doi.org/10.1111/j.1365-2 $648.2007 .04490 . x$

[23] Andersson BE, Nilsson SG. Studies in reliability and validity of the critical incident technique. J App Psych. 1964; 48: 398-403. http://dx.doi.org/10.1037/h0042025

[24] Fridlund B, Hildingh C. Qualitative Research Methods in the Service of Health. Lund, Studentlitteratur. 2000.

[25] Andersson BE, Nilsson SG. Arbets- och utbildningsanalyser med hjälp av critical incident metoden. Stockholm, Läromedelsförlaget. 1966.

[26] Drieschner KH, Lammers SMM, Van der staak CPF. Treatment motivation: an attempt for clarification of an ambiguous concept. Clin Psych Rev. 2004; 23: 1115-37. http://dx.doi.org/10.1016/j .cpr.2003.09.003

[27] Deci EL, Ryan RM. Handbook of self-determination research. NY, University of Rochester Press. 2002.

[28] Stålkrantz A, Broström A, Wiberg J, Svanborg E, Malm D. Everyday life for the spouses of patients with untreated OSA syndrome. Scand J Caring Sc. 2012; 26: 324-32. PMid: 22077540. http://dx.doi.org/10.1111/j.1471-6712.2011.00937.x

[29] Elfström M, Karlsson S, Nilsen P, Fridlund B, Svanborg E, Broström A. Decisive situations affecting partners' support to continuous positive airway pressure-treated patients with obstructive sleep apnea syndrome. A critical incident technique analysis of the initial treatment phase. J Card Nurs. 2012; 3: 228-39. PMid: 21743345. http://dx.doi.org/10.1097/JCN. 0b013e3182189c34

[30] Nilsen P, Roback K, Broström A, Ellström P-E. Creatures of habit: accounting for the role of habit in implementation research on clinical behavior change. Impl Sc. 2012; 7: 53. PMid: 22682656. http://dx.doi.org/10.1186/1748-5908-7-53

[31] Verplanken B, Aarts H. Habit attitude and planned behaviour: is habit an empty construct or an interesting case of goal-directed automaticity? Eur Rev Soc Psych. 1999; 10: 101-34. http://dx.d oi .org/10.1080/14792779943000035

[32] Gollwitzer PM. Implementation intentions strong effects of simple plans. Am Psych. 2008; 19(54): 493-503.

[33] Broström A, Nilsen P, Gardner B, Johansson P, Ulander M, Fridlund B, et al. Validation of the CPAP Habit Index-5: A Tool to Understand Adherence to CPAP Treatment in Patients with Obstructive Sleep Apnea. Sleep Disord. 2014; 929057. PMid: 24876975. http://dx.doi.org/10.1155/2014/929057

[34] Miller WR, Rollnick S. Ten things that motivational interviewing is not. Behav Cogn Psych. 2009; 37: 129-40. PMid: 19364414. http://dx.doi.org/10.1017/S1352465809005128

[35] Broström A, Strömberg A, Ulander M, Fridlund B, Mårtensson J, Svanborg E. Perceived informational needs, side-effects and their consequences on adherence - A comparison between CPAP treated patients with OSAS and healthcare personnel. Pat Ed Couns. 2009; 74: 228-35. PMid: 18835124. http://dx.doi.org/10.1016/j .pec.2008.08.012

[36] Broström A, Fridlund B, Ulander M, Sunnergren O, Svanborg E, Nilsen P. A mixed method of a group-based educational programme for CPAP use in patients with obstructive sleep apnea. J Ev Clin Pract. 2013; 1: 173-84. PMid: 22171746. http://dx.doi.org/1 $0.1111 / j .1365-2753.2011 .01797 . x$

[37] Charles C, Gafni A, Whelan T. Shared decision-making in the medical encounter: what does it mean? (or it takes at least two to tango). Soc Sc Med. 1997; 44: 681-92. http://dx.doi.org/10.1016/S 0277-9536 (96) 00221-3

[38] Makoul G, Clayman ML. An integrative model of shared decision making in medical encounters. Pat Ed Couns. 2006; 60: 301-12. PMid: 16051459. http://dx.doi.org/10.1016/j.pec. 2005. 06.010 